\title{
Using Local Data To Advance Quantitative Literacy
}

\section{Stephen Sweet}

Dept. of Sociology, Ithaca College, ssweet@ithaca.edu

Susanne Morgan

Dept. of Sociology, Ithaca College, morgan@ithaca.edu

Danette Ifert Johnson

Dept. of Speech Communication, Ithaca College, djohnson@ithaca.edu

Follow this and additional works at: https://digitalcommons.usf.edu/numeracy

Part of the Mathematics Commons, and the Science and Mathematics Education Commons

\section{Recommended Citation}

Sweet, Stephen, Susanne Morgan, and Danette Ifert Johnson. "Using Local Data To Advance Quantitative Literacy." Numeracy 1, Iss. 2 (2008): Article 4. DOI: http://dx.doi.org/10.5038/1936-4660.1.2.4 


\title{
Using Local Data To Advance Quantitative Literacy
}

\author{
Abstract \\ In this article we consider the application of local data as a means of advancing quantitative literacy. We \\ illustrate the use of three different sources of local data: institutional data, Census data, and the National \\ College Health Assessment survey. Our learning modules are applied in courses in sociology and \\ communication, but the strategy of using local data can be integrated beyond these disciplinary \\ boundaries. We demonstrate how these data can be used to stimulate student interests in class \\ discussion, advance analytic skills, as well as develop capacities in written and verbal communication. \\ We conclude by considering concerns that may influence the types of local data used and the challenges \\ of integrating these data in a course in which quantitative analysis is not typically part of the curriculum.

\section{Keywords} \\ quantitative literacy, statistics, teaching

\section{Creative Commons License} \\ (c) (i) (8)
}

This work is licensed under a Creative Commons Attribution-Noncommercial 4.0 License 


\section{Introduction}

Many professional organizations, representing a diverse range of disciplines, have published and/or endorsed statements supporting the advancement of quantitative literacy. For example, the American Sociological Association recommends engaging students in data analysis early in the sociology major and continuing to do so with increasing sophistication as they progress through the program (Howery and Rodriguez 2006; McKinney et al. 2004; Sweet and Strand 2006). Sociologists are not alone in making this type of recommendation. A report published by the Mathematical Association of America (Sons 1996) advocates challenging students to apply mathematic reasoning "to real world problems" and developing their skills to present mathematical information "symbolically, visually, numerically, and verbally." Likewise, a task force for the American Psychological Association recommended teaching students to apply research methods in research design, data analysis, and interpretation (American Psychological Association 2002).

Much discussion has focused on the notorious fear students have of statistics and math (e.g., DeCesare 2007). Our classroom experiences suggest that even if students do not fear statistics (as DeCesare argues), using local data can spark student interest and make their data analysis assignments come alive. Our strategy of advancing quantitative literacy, therefore, is to ask our students to use statistics to understand social relationships in their own communities. This pedagogy, informed by Deweyian educational theory (Dewey 1916), taps into students' natural interests to explore and understand their social worlds.

In this article, we illustrate some of the ways we have integrated local data into our courses, as well as assess learning outcomes and logistical concerns. The first activity we describe uses institutional data as a means of stimulating interest in course content. This approach can be modified for application in a wide variety of courses. The second activity, involving the analysis of Census data at the national and local levels, was designed for use in a sociology course, but it may be modified for application in other disciplines that utilize census information. The third illustration considers the application of local data in a course taught in a communication department, a venue in which data analysis is less commonly included in the curriculum. Our concluding comments consider the challenges of integrating local data, based on our experiences in designing and applying these learning modules. 


\section{Illustration 1: Integrating Institutional Data in Class Discussions}

\section{Overview}

The structures and operations of colleges and universities are oftentimes comparable to those of society as a whole, and this observation suggests that these institutions may be considered as microcosms of a larger social order (Sweet 2001). Fortunately, virtually all colleges and universities engage in institutional research. One product of these efforts is the generation of a variety of interesting statistics that can be used to understand the composition and characteristics of faculty, staff, and students. Some information is immediately obtainable through college Web sites. In other instances, institutional research departments may be able to provide more detailed analyses or even the original data. The use of such archival data has a long history in sociological research, and so bringing this resource to the classroom is a natural extension (Webb et al. 1999).

To illustrate one means of applying institutional data, Table 1 shows information presented to students in the first week of Introduction to Sociology, a course that many students take in their freshman year. The data for Ithaca College were pulled from the Web site maintained by the college's office of institutional research, as is required for all institutions. Comparative data for the United States were drawn from the Chronicle of Higher Education (2004).

\begin{tabular}{|lccc|}
\hline $\begin{array}{l}\text { Table 1. Demographic Characteristics of Faculty and Students at Ithaca } \\
\text { College and in the United States }\end{array}$ & $\begin{array}{l}\text { Ithaca } \\
\text { College }\end{array}$ & $\begin{array}{l}\text { All Colleges and } \\
\text { Universities }\end{array}$ & USA \\
\hline $\begin{array}{l}\text { Demographics } \\
\text { Students }\end{array}$ & $58 \%$ & $56 \%$ & $51 \%$ \\
$\begin{array}{l}\text { Percent Female } \\
\text { Percent Racial Minorities }\end{array}$ & $6 \%$ & $29 \%$ & $33 \%$ \\
Faculty & & & \\
$\begin{array}{l}\text { Women as Percent of Associate } \\
\text { and Full Professors }\end{array}$ & $33 \%$ & $19 \%$ & \\
$\begin{array}{l}\text { Racial Minorities as Percent of Full } \\
\text { Time Faculty }\end{array}$ & $8 \%$ & & \\
\hline
\end{tabular}


We use this table to ask students to consider the sources of disparities between the composition of their college and the wider society. Discussions of these data compel students to recognize structural barriers to social mobility and consider reasons why women faculty and minorities are under-represented at Ithaca College. Beyond this, introducing a quantitative data analysis activity in the first week of classes demonstrates to students that quantitative information is not particularly intimidating and can be useful in understanding the structure of society.

\section{Assessment}

As this learning activity takes the form of a class discussion in the first week of class, our assessment is based on the level of interest that this type of activity generated among students. Usually "interest" is not considered a sufficient metric for evaluating the success of a learning module. But in this case, the learning activity is intended primarily to pique enthusiasm for the course, as well as to establish the case that sociological analysis is an empirically driven enterprise. As most students in these discussion-oriented classes are freshmen, they demonstrated a keen interest in learning about their new home away from home, understanding its composition, and considering the factors that may have drawn others to this same community. These students came to the college with an existing understanding of "agency," - that people make choices that influence their biographies. They were commonly less familiar with the social patterns created by structural and cultural barriers. The analyses of gender and racial disparities between Ithaca College and other institutions of higher education, as well as how Ithaca College contrasts with the U.S. as a whole, forced them to consider these factors - concerns that were to be revisited throughout the course.

\section{Illustration 2: Engaging Students in the Analysis of Census Data at Local Levels}

\section{Overview}

This exercise, applied in Introduction to Sociology, requires students to use CensusScope $^{1}$ to identify income distributions and racial compositions in four counties and at the national level using data from the 2000 Census. Students make tables and a graphic display of their observations that detail variation in

\footnotetext{
${ }^{1}$ http://www.censusscope.org (accessed June 13 2008)
} 
county-level demographics. They describe the distributions and consider how the experience of being poor may vary depending on community context. Development of this learning module was supported by the American Sociological Association's Integrating Data Analysis in the Curriculum initiative ${ }^{2}$ (Carla Howery and Havidan Rodriguez co-PIs). It was designed by an instructor who had considerable experience structuring quantitatively oriented learning modules, including those contained in a textbook (Sweet and Grace-Martin 2008) on the use of the Statistical Package for the Social Sciences (SPSS).

The counties studied in this exercise can be changed, of course, depending on the issues the instructor would like to examine with students. Tompkins County is the location of Ithaca College, and instructors can substitute the county of their own school if replicating this assignment. Bennett County South Dakota is the location of the Pine Ridge Indian Reservation, a place of considerable poverty. Tunica County Mississippi is situated in a historically poor area in the Deep South in which the majority of residents are African American. Students compared these places with their home counties and with aggregate data for the United States.

This assignment contributed to quantitative literacy by teaching students how to access data from the U.S. Census, the technical skills of creating graphic displays of data, and rationales for recoding data into meaningful categories (in our case the percent of households living near or below poverty thresholds). The exercise challenged students to convert statistical information into prose and to describe the extent of inequality. As students performed these activities, they learned about distributions of income and race and how those distributions vary by geography within the United States, a fundamental building block for sociological discussions of inequality and opportunity.

In terms of sociological analysis, the most intriguing aspect of this assignment is the consideration of the intersection of personal characteristics (what it would be like to be poor) with community contexts. These types of contextual dynamics spark considerable interest among sociologists, such as those studying the "new poverty" created by hyperghettoization of the poor (Sampson, Morenoff, and Gannon-Rowley 2002; Wilson 1997). Understanding multi-level dynamics (e.g., being poor in a poor community) is quite challenging, as it requires considering the resources that individuals possess and how these intersect with resources allocated at the community level (Swisher 2006). Of course students are not prepared to perform hierarchical regressions at this stage of their education, but they can be prepared to think about data and relationships according to the theoretical constructs that underpin multi-level analyses. The assignment also opened opportunities to discuss survey design, the construction of

${ }^{2}$ http://www.asanet.org/cs/root/topnav/sociology_depts/a_brief_summary_of_the_integrating_data _analysis_project_ida (accessed June 132008 _ 
racial classifications, and how people are assigned (and assign themselves) into racial categories.

\section{Learning Objectives}

1. To understand the income distribution in the United States in 2000 .

2. To understand the representation of racial minorities in the United States in 2000.

3. To recognize the degree of geographic variation in income and ethnic composition.

4. To consider how life chances are associated with the social contexts of place.

5. To develop informative visual displays of data through graphs.

6. To develop skills in translating statistical information into written descriptions.

\section{Materials and Instruction Given to Students}

In this exercise you will examine social inequality at the community level, looking at income distributions in the U.S. and in different places within the U.S., as well as the ways in which ethnic groups are segregated by geographic area.

You will use actual data drawn from the 2000 Census of the United States to compare the place where you currently live, and places where you have lived, with the national distribution. You will also examine some other places in Mississippi and South Dakota. Why these places? Explore and you will see.

Crunch the numbers, reflect on them, and answer the questions that follow.

Instructions- You will create two tables, one representing distributions of incomes and another representing distributions of racial/ethnic groups.

Step 1. Go to CensusScope at http://www.censusscope.org/

Step 2. On Census Trend Charts click "INCOME". This will offer data on the household income in the United States in 2000. Household income reflects the combined income of all members of the family. Fill in the data for USA in Table (below). You can round decimals, such that $9.54 \%$ is rounded to $10 \%$. Fill in the column on the table below under USA. At the bottom of the table, sum the initial three rows of percentages to determine the percent of 
households earning $\$ 25,000 /$ year or less.

Step 3 Examine the degree to which Tompkins County NY (which encompasses Ithaca, NY), compares with the national income distribution. To do this, go to CHANGE LOCATION. Click the radio button for CHOOSE STATE. Select New York on the dropdown menu and click VIEW CHART. This gives you the income distribution for New York State. We want to look at a more restricted geographic area, so go again to the CHANGE LOCATION menu, click the radio button for CHOOSE COUNTY, and select Tompkins County. How do these numbers compare with the national distributions? Fill in the chart. When done, ZOOM OUT twice so that you can return to select a new state.

Step 4. Replicate the previous sequences to find the income distribution for the county of your hometown and fill in those numbers. Now step back. How does your home county compare to Tompkins County and the U.S.? Note, if you grew up in Tompkins county, select another county, perhaps a vacation spot, someplace where you might want to live, the home county of the president; it's your call.

Step 5. Now look at Tunica County Mississippi, fill in the statistics and reflect on differences between that area and your home county.

Step 6. Now look at Bennett County South Dakota, fill in the statistics and reflect on differences observed.

Step 7. Go to CensusScope at http://www.censusscope.org/

Step 8. On Census Trend Charts click "POPULATON BY RACE". This will offer data on racial composition of the 2000 Census, as well as other years. Fill in data for the USA in the second Table.

Step 9. Now examine how Tompkins County NY (which encompasses Ithaca, NY), compares with the national racial distributions. To do this, go to CHANGE LOCATION. Click the radio button for CHOOSE STATE. Select New York on the drop-down menu and click VIEW CHART. This gives you the income distribution for New York State. We want to look at a more restricted geographic area, so go again to the CHANGE LOCATION menu, click the radio button for CHOOSE COUNTY, and select Tompkins County. How do these numbers compare with the national distributions? Fill in the chart. When done, ZOOM OUT twice so that you can return to select a new state.

Step 10. Replicate the previous sequences to find the racial distribution for the county of your home town and fill in those numbers. Now step back. How does your home county compare to Tompkins 
County and the U.S.? Note, if you grew up in Tompkins county, select another county, perhaps a vacation spot, someplace where you might want to live, the home town of the president, it's your call.

Step 11. Now look at Tunica County Mississippi. Reflect on how those statistics compare to the places your have already examined.

Step 12. Now look at Bennett County South Dakota, fill in the statistics, and reflect on the findings.

Household Income Distributions in the United States in 2000. (Answers filled in by students using CensusScope))

\begin{tabular}{|c|c|c|c|c|c|}
\hline Income & USA & $\begin{array}{c}\text { Tompkins } \\
\text { County NY } \\
\text { (Ithaca) }\end{array}$ & $\begin{array}{l}\text { Your } \\
\text { Home } \\
\text { Town } \\
\end{array}$ & $\begin{array}{l}\text { Tunica } \\
\text { County } \\
\text { Miss. }\end{array}$ & $\begin{array}{c}\text { Bennett } \\
\text { County } \\
\text { South } \\
\text { Dakota }\end{array}$ \\
\hline$<\$ 9999$ & $10 \%$ & $12 \%$ & Answers & $23 \%$ & $20 \%$ \\
\hline \$10K-\$14999 & $6 \%$ & $8 \%$ & Vary & $12 \%$ & $11 \%$ \\
\hline \$15K-\$24999 & $13 \%$ & $15 \%$ & & $18 \%$ & $19 \%$ \\
\hline \$25K-\$34999 & $13 \%$ & $12 \%$ & & $14 \%$ & $19 \%$ \\
\hline \$35K-\$49999 & $17 \%$ & $16 \%$ & & $12 \%$ & $14 \%$ \\
\hline \$50K-\$74999 & $20 \%$ & $19 \%$ & & $14 \%$ & $11 \%$ \\
\hline \$75K-\$99999 & $10 \%$ & $8 \%$ & & $5 \%$ & $5 \%$ \\
\hline $\begin{array}{l}\text { \$100K- } \\
\$ 149999\end{array}$ & $8 \%$ & $7 \%$ & & $2 \%$ & $2 \%$ \\
\hline $\begin{array}{l}\$ 150 \mathrm{~K}- \\
\$ 199999\end{array}$ & $2 \%$ & $2 \%$ & & $0 \%$ & $0 \%$ \\
\hline$\$ 200,000+$ & $2 \%$ & $2 \%$ & & $1 \%$ & $0 \%$ \\
\hline $\begin{array}{l}\text { Calculate the } \\
\text { percent of } \\
\text { households } \\
\text { with incomes } \\
\text { below } \\
\$ 25,000 \text {. }\end{array}$ & $29 \%$ & $35 \%$ & & $52 \%$ & $49 \%$ \\
\hline
\end{tabular}




\begin{tabular}{|c|c|c|c|c|c|}
\hline \multicolumn{6}{|c|}{$\begin{array}{l}\text { Racial Variation in The United States in 2000. (Answers filled in by } \\
\text { students using CensusScope) }\end{array}$} \\
\hline Race & USA & $\begin{array}{c}\text { Tompkins } \\
\text { County NY } \\
\text { (Ithaca) }\end{array}$ & $\begin{array}{l}\text { Your } \\
\text { Home } \\
\text { Town }\end{array}$ & $\begin{array}{c}\text { Tunica } \\
\text { County } \\
\text { Miss. }\end{array}$ & $\begin{array}{c}\text { Bennett } \\
\text { County } \\
\text { South } \\
\text { Dakota }\end{array}$ \\
\hline Hispanic & $13 \%$ & $3 \%$ & Answers & $3 \%$ & $2 \%$ \\
\hline White & $69 \%$ & $84 \%$ & Vary & $27 \%$ & $41 \%$ \\
\hline Black & $12 \%$ & $3 \%$ & & $70 \%$ & $0 \%$ \\
\hline $\begin{array}{l}\text { American } \\
\text { Indian and } \\
\text { Eskimo }\end{array}$ & $1 \%$ & $0 \%$ & & $0 \%$ & $51 \%$ \\
\hline Asian & $4 \%$ & $7 \%$ & & $0 \%$ & $0 \%$ \\
\hline $\begin{array}{l}\text { Hawaiian and } \\
\text { Pacific }\end{array}$ & $0 \%$ & $0 \%$ & & $0 \%$ & $0 \%$ \\
\hline $\begin{array}{l}\text { lslander } \\
\text { Other }\end{array}$ & $0 \%$ & $0 \%$ & & $0 \%$ & $0 \%$ \\
\hline $\begin{array}{l}\text { Two or More } \\
\text { Races }\end{array}$ & $2 \%$ & $2 \%$ & & $1 \%$ & $6 \%$ \\
\hline
\end{tabular}

\section{Analysis Questions}

1. Create a bar graph comparing the percentages of households living at or near poverty level (incomes of $\$ 25,000$ or less) in the four counties using PowerPoint. Make sure the graph includes a meaningful title, labeled axes, and is appropriately scaled.

2. Compare the incomes received in these different places in our nation and how inequality evidenced in each place as compared to the income distribution in the United States. Why do you think these differences exist?

3. Compare the racial/ethnic composition of these different places as compared to the distribution in the United States. Why do you think these differences exist?

\section{Reflection Questions}

4. Consider lives lived in a social context and reflect on the life chances of 
four poor children, one from Tunica County, one from Bennett County, one from Tompkins County, and one from your home county. Would these different social contexts have an impact on their lives? How?

5. Are there any types of social programs that would help alleviate the problems you identify?

\section{Grading System}

Table 1 filled in correctly (10 Points)

Table 2 filled in correctly (10 Points)

Graph construction (10 Points)

Question 1 Major differences identified and coherently summarized (10 points)

Question 1 Causes for economic inequality considered (10 points)

Question 2 Major differences identified and coherently summarized (10 points)

Question 2 Causes for racial/ethnic segregation considered (10 points)

Question 3 Linkages are made between opportunities and community economic resources (20 Points)

Question 4 Social policies relating to opportunity, economic inequality, and race/ethnicity are discussed (10 Points) Extensive grammar or proofreading errors (subtract 10 points) Total Grade

\section{Assessment}

This exercise has been used in three large sections (250 student capacity) of Introduction to Sociology. Most students in these classes were of freshman or sophomore standing and were not sociology majors. The assignment, collected in the ninth week of the semester, was scored by undergraduate teaching assistants who were trained to mark each component as satisfied (full credit) or not satisfied (no credit). In the event that students did not receive credit for any component of the assignment, they were given an opportunity to rewrite and resubmit their work. In the most recent class, the average grade for this assignment was $96.4 \%$ $(N=216)$, with the lowest grade being $40 \%$. Over three fourths of the class (77.4\%) received full credit for all components.

To examine the assignment's impact on knowledge of variation in social inequality we implemented a pre-test/post-test assessment. The following 
questions were asked of students on the first day of the semester, and then again on the second examination (approximately eleven weeks later, the correct answers are bolded here):

1. Compared to the national averages, the income earned in a rural community in Mississippi is... (a) dramatically lower, (b) slightly lower, (c) about the same (d) slightly higher, (e) much higher.

2. Compared to the national averages, the income earned in a rural community in South Dakota is...(a) dramatically lower, (b) slightly lower, (c) about the same (d) slightly higher, (e) much higher.

3. Compared with the U.S. averages, the ethnic composition of a rural community in Mississippi is disproportionately...(a) White, (b) Black, (c) Latino, (d) Native American, (e) Eastern European.

4. Approximately what percent of households in the U.S. have an income less than $\$ 25,000 /$ year? (a) $2 \%$, (b) $5 \%$, (c) $10 \%$, (d) $25 \%$, (e) $50 \%$.

Table 2 reveals considerable improvements in knowledge of racial and economic structures.

\begin{tabular}{|lcc|}
\hline $\begin{array}{l}\text { Table 2. Knowledge Retention From Analysis of Local Data Using } \\
\text { CensusScope }\end{array}$ & Pre-Test & Post-Test \\
\hline Exam Question & $45 \%$ & $85 \%$ \\
\hline Extent of Poverty in Mississippi & $62 \%$ & $94 \%$ \\
Extent of Poverty in Rural South Dakota & $69 \%$ & $95 \%$ \\
Racial Composition of Mississippi & $30 \%$ & $55 \%$ \\
\hline
\end{tabular}

\section{Illustration 3: Applying Local Data From The National College Health Assessment Data}

\section{Overview}

In this illustration we outline a strategy of integrating a quantitative analysis component in the course Business and Professional Communication. While sharing the same goal of increasing students' ability to analyze and present 
quantitative information, this teaching module differed from the previously discussed module in three important ways. First, this was a first attempt of an experienced instructor to integrate a quantitative analysis component in her course. Second, the analysis of local data was introduced into a communication department curriculum, where quantitative skills are commonly not taught. Third, its application involved the use of a statistical program and a more elaborate data set than the above illustrations.

This teaching module was developed through a joint project of the Ithaca College Center for Faculty Excellence and the Ithaca College Health Promotion Program to integrate the analysis of the National College Health Assessment $(\mathrm{NCHA})^{3}$ in courses on campus. The NCHA is a national survey conducted by the American College Health Association (ACHA.) Since inception of the NCHA in 1998, more than 375,000 students at nearly 350 colleges and universities across the country have taken the survey. It has been used by two-year and four-year public and private institutions from various geographical regions and can be analyzed according to student demographics, as well as by Carnegie Foundation classifications. Survey topics include alcohol, tobacco, and other drug use; sexual health; weight, nutrition, and exercise; mental health; and personal safety and violence. National results are available online ${ }^{4}$ and the raw data are provided to participating colleges through the American College Health Association.

Students were placed in pairs and were instructed to prepare a 5-7 minute presentation on the NCHA data representing the activities and behaviors at Ithaca College To help allay anxiety, as well as socialize collaborative work skills, students were assigned to work in teams of two. One class period was devoted to explaining the NCHA and the types of questions it addressed. Lists of questions from the NCHA were provided to each pair of students so that they could identify topics of interest. Each pair then selected a survey question or set of questions that would be the focus of the presentation based on Ithaca College data from the NCHA. Students analyzed data using SPSS and received coaching on how to use this program during one class session. Most students examined frequency data, while some with more experience with quantitative information also tested bivariate relationships using ANOVA and/or Pearson's correlation techniques.

In 2007, some of the topics addressed included student engagement in "safer" drinking behavior (e.g., using a designated driver, choosing not to drink on some occasions); reported rates of hopelessness and depression; frequencies of alcohol and cigarette use; and post-drinking involvement in physical altercations and unprotected sex. Allowing student teams to select their own topic was intended to increase ownership of the project and interest in the data for both the student presenters and their peers in the audience. Each pair of students conducted

\footnotetext{
${ }^{3}$ http://www.acha-ncha.org/overview.html (accessed June 13 2008)

${ }^{4}$ http://www.acha-ncha.org/data_highlights.html (accessed June 13 2008)
} 
background research on the topic in order to compare their analysis of local data with existing studies on related issues.

Students were required to include discussion of at least three outside sources that were relevant to their topic and that met standards for quality evidence discussed earlier in the course (accuracy, source credibility, recency, relevance, sufficiency). Students included scholarly articles, stories from popular magazines and newspapers (e.g., Time magazine, The Washington Post), and information from organizational or governmental Web sites (e.g. The Centers for Disease Control and Prevention). These sources were included so that students would have a context for interpreting the NCHA data and to help inform their analyses. Each presentation was followed by a brief quiz intended to provide presenters and instructor feedback on how well the audience understood the presentation.

In advance of their formal presentation, presenters met with the instructor to examine their initial findings and analyses of the NCHA data. This meeting allowed the instructor to answer any questions about data analysis or interpretation, as well as to provide feedback on drafts of tables or graphs.

\section{Learning Objectives}

1. Develop skills to incorporate data analysis in a public presentation.

2. Develop skills needed for the construction of tables and graphs.

3. Develop skills for oral presentations.

\section{Materials and Instruction Given to Students}

\section{The purpose of this presentation is to understand and interpret quantitative information and convey quantitative information to an audience clearly and accurately. You will work in pairs to develop and present information from the National College Health Assessment (NCHA). Your team will conduct background research on a topic that is addressed in the NCHA dataset and develop a research question that can be answered by analyzing the NCHA data (e.g., What is the relationship between individual reports of number of sexual partners and perceptions of what is typical among Ithaca College students [questions 20, 22]?). Your team will meet with the instructor to discuss options for data analysis (e.g., frequencies, comparison of means, correlations) and, with the instructor's assistance as needed, will conduct data analysis for presentation using SPSS. \\ Presentations must include tabular or graphical representation of quantitative information from the NCHA. Presentations will be 5-7 minutes long and delivered extemporaneously (i.e., maximum of one notecard per presenter) on the date assigned. Both partners in your team must speak during the presentation.}


The grading rubric for this presentation appears at the end of the syllabus. ${ }^{5}$ Please take particular note of new rubric categories for this assignment that have been added since your last presentation: demonstrates understanding of quantitative information, presentation aids, and references. Short quizzes will be administered to the class after presentations; these quizzes will provide feedback to presenters about the clarity of their presentations.

\section{Assessment}

Student performance on the grading rubric (Appendix A) offers one means of assessing the effectiveness of this module. Mean scores, standard deviations and maximum values are in Table 3 .

\begin{tabular}{|lccc|}
\hline \multicolumn{3}{|l}{ Table 3: Student NCHA Presentation Performance: Summary Statistics } \\
\hline Rubric Area & $\begin{array}{c}\text { Maximum } \\
\text { Possible }\end{array}$ & $\begin{array}{c}\text { Mean } \\
\text { Score }\end{array}$ & $\begin{array}{c}\text { Standard } \\
\text { Deviation }\end{array}$ \\
\hline Time requirements & 2 & 2.0 & 0.0 \\
Audience adaptation & 3 & 2.3 & 0.5 \\
Introduction & 3 & 2.3 & 0.5 \\
Thesis statement & 2 & 2.0 & 0.0 \\
Conclusion & 2 & 1.6 & 0.5 \\
Organization & 4 & 3.8 & 0.4 \\
Understands quantitative & 6 & 4.9 & 1.2 \\
results & & & \\
Presentation aids & 5 & 4.7 & 0.5 \\
Source citation & 3 & 1.3 & 1.0 \\
Word usage & 3 & 3.0 & 0.0 \\
Vocal delivery & 4 & 3.4 & 0.9 \\
Physical delivery & 4 & 3.2 & 0.4 \\
Extemporaneous style & 3 & 2.7 & 0.5 \\
Reference page & 5 & 3.8 & 1.6 \\
\hline
\end{tabular}

Examining the mean scores reveals that presentation skills tended to be strong, as were organization, delivery, and student performance. Source citation and inclusion of an appropriate reference page were areas that showed substantial

${ }^{5}$ Appendix A 
room for improvement as well (a common observation in other modules in this course). But perhaps of greatest concern is the observation that most students achieved good, but not excellent, understanding of the quantitative information they presented. For example, in a few cases students presented findings that did not accurately reveal what the data indicated. Additionally, the depth of analysis varied greatly. For example, while some pairs focused solely on frequency data, other student teams attempted to also include analyses of group differences, but with varying levels of competency. These findings suggest that any future effort to replicate or modify this module should involve structuring additional discussion of statistical techniques and expectations of data analysis with the students.

A second method of assessment involved having peers complete short quizzes after the presentations. These quizzes focused on the NCHA data, statistical concepts introduced during the presentations and the conclusions drawn from these data. There were nine presentation pairs. For five of the presentations, $77 \%$ or more of students correctly answered the quiz question. For two additional presentations, 58-60\% answered correctly. For one question, 53\% (9/17) of students answered the question correctly but six of those nine students indicated that they understood the statistical concept before the presentation. For one presentation, no students answered the question correctly; but this was not surprising, as this particular presentation contained multiple inaccuracies in information. In the end, we concluded that this first attempt at integrating a data analysis/presentation of local data assignment in a communications course had mixed, but promising, results.

\section{Discussion and Suggestions}

In this article we have illustrated some possibilities for integrating local data in the class assignments and discussions. Our experience is that students respond with great interest to these types of data. They view quantitative information not as knowledge they may need "when they get into the real world" but as immediately useful in understanding structures, cultures, and behaviors that have already affected their lives. This is evident in their responses during class discussions, in their written presentations of quantitative analyses, and in their oral presentations. We believe that many students could benefit by instructors replicating, modifying, or designing assignments similar to those illustrated here. The approaches we used present opportunities for students to develop fundamental skills in data analysis, to present quantitative information, and to link data analysis to theory. While our examples were drawn from our courses in sociology and communication, the application of local data is certainly not

restricted to these disciplines. With this being said, we conclude with some 
caveats - considerations instructors will want to keep in mind if they seek to pursue similar activities that rely on local data.

Our experience in the communication course indicated that students need to receive considerable guidance in handling quantitative data analysis. Instructors who do not customarily teach statistically-oriented courses may experience a steep learning curve as they gain experience framing expectations for students and teaching the mechanics of data analysis. The instructor of this course concluded that, if she were to integrate this module into a future course, she would need to spend considerably more time on the process of analyzing data. However, this will likely impact the time available for the delivery of other content.

The application of online tools such as CensusScope offers user-friendly means of accessing data online. Similar types of applications are available for other databases (see Scheitle 2006). In this paper we suggested that analysis of some of these publicly available data sets can be modified so that students analyze data at the local level and thus gain an understanding of the social world they inhabit. But efforts to reduce data to subsamples can introduce data management commitments on the part of instructors, as well as influence the capacity to create robust analyses. Instructors will want to consider these types of concerns in advance of structuring assignments.

Note that our illustrations do not include data that students could conceivably collect on each other. Such activities would likely require approval of institutional review boards (delaying implememention) and also would be likely prevent the collection of the types of data students are likely to find of greatest interest. Beyond this, students will inevitably question if their samples are representative, and sample sizes will also limit the types of analyses that can be performed. While it is possible to generate new data, instructors will want to consider the impact this will have on their own workloads, as it can introduce significant data management concerns (such as survey instrument construction) as well as the potential harm that could result from breaches of student anonymity.

Finally, we have suggested that institutional data can be an interesting source of analysis and class discussions, but the application of these data in classroom activities can present concerns. In some instances, colleges and universities may wish to have some data remain restricted, especially if it could affect their public image or recruitment efforts. And there is some risk to the institution if students engage in faulty analyses and publicize their findings. Owing to other obligations, institutional research departments may not be able to respond to numerous requests for data that may be needed for class activities. They also may not be able to provide primary data owing to human subjects concerns and legal obligations such as those stipulated by the Family Educational Rights and Privacy Act 
We offer these cautionary comments to help others consider how to use local data in the classroom and engage in the broad objective of cultivating quantitative literacy. Our use of local data with undergraduate students is intended, in part, to counter resistance to statistical inquiry and to build interest in performing analyses. Our experiences affirm that, as students consider their social worlds through the use of local data, quantitative analysis becomes relevant to their lived experiences, stimulates student interest, and results in learning. Although the use of local data presents some logistical concerns, our assessments indicate that this is a pedagogical approach worth considering.

\section{Acknowledgments}

The authors thank the four anonymous reviewers and editor Len Vacher for comments on an earlier version of this article.

\section{References}

American Psychological Association. 2002. Undergraduate psychology major learning goals and outcomes: A report. Task Force on Undergraduate Psychology Major Competencies, Jane S. Halonen, Chair, http://www.apa. org/ed/pcue/taskforcereport.pdf

Chronicle of Higher Education. 2004. Trends in faculty employment. Chronicle of Higher Education Almanac, August 27, 2004, p. 28.

DeCesare, Michael. 2007. Statistics anxiety among sociology majors: A first diagnosis and some treatment options. Teaching Sociology 35: 360-367. http://dx.doi.org/10.1177/0092055X0703500405

Dewey, John. 1916. Democracy and education. NewYork: Macmillan.

Howery, Carla and Havidan Rodriguez. 2006. Integrating data analysis: Working with sociology departments to address the scientific literacy gap. Teaching Sociology 34: 5-22. http://dx.doi.org/10.1177/0092055X0603400103

McKinney, Kathleen, Carla Howery, Kerry Strand, Edward Kain, and Catherine White Berheide. 2004. Liberal learning and the sociology major updated: Meeting the challenge of teaching sociology in the twenty-first century. Washington DC: American Sociological Association.

Sampson, Robert, Jeffrey D. Morenoff, and Thomas Gannon-Rowley. 2002. Assessing "neighborhood effects": Social processes and new directions in research. Annual Review of Sociology 51: 443-478. http://dx.doi.org/10.1146/ annurev.soc.28.110601.141114 
Scheitle, Chris. 2006. Incorporating web-based data analysis into the introductory curriculum. Teaching Sociology 34: 80-86. http://dx.doi.org/10.1177/ 0092055X0603400108

Sons, Linda. ed. Quantitative reasoning for college graduates: A complement to the standards. Washington DC: Mathematical Association of America. http://www.maa.org/past/q1/q1_toc.html.

Sweet, Stephen. 2001. College and society: An introduction to the sociological imagination. Boston MA: Allyn and Bacon.

Sweet, Stephen and Karen Grace-Martin. 2008. Data analysis with SPSS: A first course in applied statistics. 3rd ed. Boston, MA: Allyn and Bacon.

Sweet, Stephen and Kerry Strand. 2006. "Cultivating quantitative literacy: The role of sociology." Teaching Sociology 34: 1-4. http://dx.doi.org/10.1177/ 0092055X0603400101

Swisher, Raymond. 2006. "Hierarchical models for work-family and life course research." In The work and family handbook: Multidisciplinary perspectives, methods and approaches, ed. M. Pitt-Catsouphes, E. E. Kossek, and S. Sweet, p. 367-386. Mahwah, NJ: Lawrence Erlbaum Associates.

Webb, Eugene, Donald Campbell, Richard Schwartz, and Lee Sechrest. 1999. Unobtrusive measures. Thousand Oaks, CA: Sage.

Wilson, W. J. 1997. When work disappears: The world of the new urban poor. New York: Alfred A. Knopf.

\section{Appendix A}

\section{National College Health Assessment (NCHA) Presentation Grading Rubric}

\section{Time requirements ( 2 pts.)}

$0=$ Presentation is more than one minute above or below time limits for assignment.

$1=$ Presentation is within one minute above or below time limits for assignment.

$2=$ Presentation is within time limits established for the assignment.

Audience analysis and adaptation ( 3 pts.)

$0=$ Attempts at audience adaptation lack clear relevance.

$1=$ Overt, relevant adaptation of topic importance, organization, supporting evidence, and delivery ( 1 of 4 ).

$2=$ Overt, relevant adaptation of topic importance, organization, supporting evidence, and delivery ( 2 of 4 ) 
3 = Overt, relevant adaptation of topic importance, organization, supporting evidence, and delivery ( 3 or 4 of 4 )

\section{Introduction contains necessary elements ( 3 pts.)}

$0=$ Some functions present but three or more main functions absent.

$1=$ Most functions present but two main functions absent or unclear.

$2=$ Attention getter trite. Most functions present but one main function absent or unclear.

$3=$ All functions of introduction present. Attention getter is unique; topic relevance and importance established. Preview of main points is present. Introduction helps establish speaker credibility and rapport. Length is proportionate to the rest of the presentation. Clear transition into body.

Thesis statement ( 2 pts.)

$0=$ Thesis is vague, is irrelevant to the body or has persuasive intent.

$1=$ Thesis is clearly stated and relevant but is too broad or narrow for presentation.

$2=$ Thesis is clearly stated, informative, appropriately narrowed, and relevant to the rest of the presentation.

\section{Conclusion contains necessary elements ( 2 pts.)}

$0=$ Two or more elements absent or unclear. Length may be disproportionate for the presentation.

$1=$ Most elements present but one element absent or unclear.

$2=$ Conclusion ties speech back to the attention getter, restates thesis, and ending statement is conclusive. Review of main points is present. Length is proportionate to the rest of the presentation.

\section{Organization clear, coherent, appropriate (4 pts.)}

$0=$ Introduction, body, or conclusion is not identifiable.

$1=$ Introduction, body and conclusion identifiable but main point organization is unclear. Transitions absent.

$2=$ Main point organization is unclear at times.

3 = Main point organization is clear. Some transitions present. Subpoints absent. Uneven development of topics.

4 = Introduction, body, conclusion identifiable. Main points and subpoints clear. Transitions effectively link points together. Development of main points is balanced.

\section{Demonstrates understanding of quantitative information (6 pts.)}

$0=$ Quantitative information is not presented. 
$1=$ Inaccuracies are present in the quantitative information discussed in both visual and verbal forms.

$2=$ Quantitative information is described accurately either verbally or visually OR explanation of statistical tests and implications of findings is absent.

3 = Quantitative information is described accurately in verbal and visual forms but lacks detail. The relevance of some information may be unclear. Explanation of statistical tests or implications of findings is absent.

4 = Quantitative information is detailed, relevant and answers the question posed. Information described accurately verbally and visually. Presenters are vague in explaining statistical tests and implications of findings.

5= Quantitative information is detailed, relevant and answers the question posed. Information described accurately verbally and visually. Presenters vague in explaining either statistical tests or implications of findings.

$6=$ Quantitative information is detailed, relevant and answers the question posed. Information described accurately verbally and visually. Statistical tests and implications of their findings are explained clearly.

\section{Presentation aids (6 pts.)}

$0=$ No presentation aids are used.

$1=$ Presentation aids are not directly tied to the verbal presentation.

$2=$ Presentation aids outline or simply repeat information from the verbal presentation and fail to meet several criteria for effectiveness.

$3=$ Presentation aids simply repeat or outline information from the verbal presentation.

$4=$ Presentation aids clarify and extend the verbal presentation. Aids fail to meet several criteria for effectiveness.

$5=$ Presentation aids clarify and extend the verbal presentation. Aids are not creative but meet most criteria for effectiveness.

$6=$ Presentation aids clarify and extend the verbal presentation. Aids are presented creatively and meet criteria for effectiveness.

\section{Source citation ( 3 pts.)}

$0=$ No external sources cited.

1 = Citation is vague (fails to include information to allow audience to assess quality) or limited to one source.

$2=$ Citation is limited to two sources.

$3=$ Multiple sources are cited with information that allows audience to assess recency, objectivity, accuracy, and relevance of evidence. Sources biases are not enough to seriously hamper credibility of information.

Word usage is appropriate (3 pts.) 
$0=$ Excessive reliance on slang and numerous grammar errors. Words used incorrectly and mispronounced.

$1=$ Multiple grammar errors and mispronunciation. Words used incorrectly.

$2=$ High level vocabulary absent. Several slang words/phrases. Two or three grammar errors.

$3=$ Word choice appropriate for college audience; no slang present. High level vocabulary explained.

\section{Vocal delivery is appropriate (4 pts.)}

$0=$ Rate, pitch, volume, or diction is distracting and hampers clear communication (3 or 4 of 4 ).

$1=$ Rate, pitch, volume, or diction is distracting and hampers clear communication (2 of 4).

$2=$ Rate, pitch, volume or diction is distracting and hampers clear communication (1 of 4$)$.

3 = Some vocalized pauses. Variety in rate, volume, and pitch is present. Overrehearsed (canned) delivery.

4 = Fluent and conversational vocal delivery. Rate, volume, and pitch show appropriate variety. Diction is clear.

\section{Physical delivery is appropriate (4 pts.)}

$0=$ Distracting posture (leaning, crossed feet, excessive movement), appearance (e.g., hair in face, repetitive actions, hands in pockets), gestures (limited, overdone), eye contact infrequent and noncomprehensive (4 of 5).

$1=$ Distracting posture, appearance, gestures, eye behavior, facial expressivity (3 of 5).

$2=$ Distracting posture, appearance, gestures, eye behavior, facial expressivity (2 of 5).

3 = Distracting posture, appearance, gestures, eye behavior, facial expressivity (1 of 5).

4 = Eye contact frequent and comprehensive. Posture and appearance appropriate for situation. Unique gestures present for emphasis and are not distracting. Facial expressivity supports content.

\section{Extemporaneous delivery style (3 pts.)}

$0=$ Delivery is impromptu, memorized or manuscript. Vocal or physical involvement is lacking.

$1=$ Extemporaneous delivery with moderate use of notes. Vocal or physical involvement is lacking.

$1=$ Extemporaneous delivery with moderate use of notes. Generally appropriate vocal and physical involvement. 
3 = Extemporaneous delivery with minimal use of notes and appropriate vocal and physical involvement.

\section{Reference page ( 5 pts.)}

$0=$ No reference page is included with presentation aids.

$1=$ One unique source is included.

$2=$ Two unique sources are included and are not formatted in APA style.

$3=$ Two unique sources are included and format is generally in APA style.

$4=$ Three unique sources are included and are not formatted in APA style.

$5=\mathrm{A}$ minimum of three unique, fully identifiable sources are included and is generally formatted in APA style. 